\title{
Dynamics of chemosensitivity and chromosomal instability in recurrent glioblastoma
}

\section{S Spiegl-Kreinecker ${ }^{1,6}$, C Pirker ${ }^{1,6}$, C Marosi $^{2}$, J Buchroithner', J Pichler ${ }^{3}$, R Silye $^{4}$, J Fischer', M Micksche ${ }^{5}$ and W Berger $* 5$}

'Departments of Neurosurgery, Wagner Jauregg Hospital, Linz, Austria; ${ }^{2}$ Clinical Division of Oncology, Department of Medicine I, Medical University Vienna, Vienna, Austria; ${ }^{3}$ Department of Internal Medicine, Wagner Jauregg Hospital, Linz, Austria; ${ }^{4}$ Institute of Pathology, Wagner Jauregg Hospital, Linz, Austria and ${ }^{5}$ Institute of Cancer Research, Department of Medicine I, Medical University Vienna, Vienna, Austria

Glioblastoma multiforme is characterised by invasive growth and frequent recurrence. Here, we have analysed chromosomal changes in comparison to tumour cell aggressiveness and chemosensitivity of three cell lines established from a primary tumour and consecutive recurrences (BTLI to BTL3) of a long-term surviving glioblastoma patient together with paraffin-embedded materials of five further cases with recurrent disease. Following surgery, the BTL patient progressed under irradiation/ lomustine but responded to temozolomide after re-operation to temozolomide. The primary tumour -derived BTLI cells showed chromosomal imbalances typical of highly aggressive glioblastomas. Interestingly, BTL2 cells established from the first recurrence developed under therapy showed signs of enhanced chromosomal instability. In contrast, BTL3 cells from the second recurrence resembled a less aggressive subclone of the primary tumour. Although BTL2 cells exhibited a highly aggressive phenotype, BTL3 cells were characterised by reduced proliferative and migratory potential. Despite persistent methylation of the $0^{6}$-methylguanine-DNA methyltransferase promoter, BTL3 cells exhibited the highest temozolomide sensitivity. A comparable situation was found in two out of five glioblastoma patients, both characterised by enhanced survival time, who also relapsed after surgery/chemotherapy with less aggressive recurrences. Taken together, our data suggest that pretreated glioblastoma patients may relapse with highly chemosensitive tumours confirming the feasibility of temozolomide treatment even in case of repeated recurrence.

British Journal of Cancer (2007) 96, 960-969. doi:I0.1038/sj.bjc.6603652 www.bjcancer.com

Published online 6 March 2007

(C) 2007 Cancer Research UK

Keywords: Recurrent glioblastoma; chemosensitivity; chromosomal instability; temozolomide; MGMT

Malignant transformation and progression is thought to be based on the stepwise accumulation of genetic changes that confer growth and survival advantages to (pre)malignant cells. Consequently, solid tumours at diagnosis are generally characterised by complex karyotypic alterations and an increasing number of chromosomal aberrations have been shown to be associated with tumour development and progression (reviewed by Albertson et al (2003)). This clonal evolution in combination with chromosomal instability may result in the development of variant subclones within one tumour harbouring different sets of genetic changes.

Human malignant gliomas represent the most common primary malignant brain tumour comprising astrocytomas, oligodendrogliomas, ependymomas, and tumours of the coroid plexus. The by far most frequent histological entity is glioblastoma (astrocytoma WHO grade IV), typically composed of different cell types displaying a wide spectrum of heterogeneity regarding morphology (referred to by the term 'multiforme'), biological aggressiveness, invasive potential, as well as treatment sensitivity (Mao and

* Correspondence: Professor W Berger;

E-mail: walter.berger@meduniwien.ac.at

This work was supported by the Forschungsförderungsfonds der Österreichische Krebshilfe Oberöstereich.

${ }^{6}$ These authors contributed equally to the main findings of the paper. Received 25 August 2006; revised 7 December 2006; accepted 30 January 2007; published online 6 March 2007
Hamoudi, 2000; Zhu and Parada, 2002). Glioblastomas arise either de novo without evidence of an antecedent lesion (primary glioblastoma) or through an anaplastic progression from a lower-grade astrocytoma (secondary glioblastoma). Genetic studies revealed that there are different distinct pathways involved in the development of these lesions. Although in primary glioblastoma loss of the tumour suppressors p16/Cdkn2/Ink4 and PTEN as well as amplifications in EGFR and HDM2 are frequent, secondary glioblastomas lose p53 already at the stage of low-grade astrocytoma (Mao and Hamoudi, 2000; Zhu and Parada, 2002).

With respect to chromosomal aberrations deletions of $1 \mathrm{p}, 9 \mathrm{p}$, $10,13 \mathrm{q}, 17 \mathrm{p}, 19 \mathrm{q}$, and 22q, and gains of chromosome 7 ( Liu et al, 1997; Rasheed et al, 1997; Duerr et al, 1998; Smith and Jenkins, 2000) are the most common in gliomas. Several genes have been identified to be associated with tumorigenesis and anaplastic progression of glioblastoma subgroups including, besides the already mentioned p16/Cdkn2/Ink4, EGFR, PTEN, p53, and HDM2 also for example cdk4, cyclin D1, PDGFR $\alpha$, k-ras, N-myc, gli, c-myc, and myb (Mao and Hamoudi, 2000; Zhu and Parada, 2002).

Despite intensive research regarding the genetics and biology, the prognosis of glioblastoma patients is still poor. Even in case of maximal therapy, median survival of glioblastoma patients remains low and ranges between 10 and 12 months, only (Scott et al, 1998). Thus, a more profound knowledge of the molecular background and cell biological behaviour of this cancer is inevitable to develop appropriate treatment strategies (Buckner, 2003). 
The current standard of care for patients with high-grade malignant glioma used to be resection followed by radiotherapy (RT). However, the use of adjuvant and/or concomitant chemotherapy and the standard of care at first relapse are still under debate (van den Bent et al, 2006). Chemotherapeutic treatment success in brain tumours is mainly limited by the blood-brain barrier and the expression of chemoresistance-related proteins like $\mathrm{P}$-glycoprotein (P-gp), multidrug resistance protein 1 (MRP1), and major vault protein (MVP) also known as lung resistance protein (LRP) (Berger et al, 2001; Bredel, 2001; Spiegl-Kreinecker et al, 2002). Based on their ability to circumvent the blood-brain barrier, alkylating agents represent the gold standard in the treatment of malignant gliomas. Besides nitrosoureas, temozolomide is the most promising drug in the current treatment of patients with malignant gliomas. Temozolomide has demonstrated a good tissue distribution, including penetration of the bloodbrain barrier and the cerebrospinal fluid (DeAngelis, 2003). Recently, a significant survival benefit for glioblastoma patients treated with temozolomide combined with RT was shown (Stupp et al, 2005). However, protection against the toxic effect of alkylating agents might rely on the activity of $O^{6}$-methylguanineDNA methyltransferase (MGMT) (Harris and Margison, 1993) a key enzyme in the DNA repair network.

In this study, we present, to the best of our knowledge, a unique glioblastoma cell model consisting of one primary tumour- and two recurrences-derived permanent cell lines from a single patient (BTL). Chromosomal changes as well as cell-biological behaviour and treatment responsiveness were compared to the respective clinical observations and to five further patients with recurrent glioblastoma (GL1-5). We demonstrate that even in case of repeated recurrence and heavy pretreatment with chemotherapy believed to be often associated with acquired chemotherapy resistance (Bredel, 2001) - glioblastoma patients may relapse with less aggressive tumours highly responsive to chemotherapy.

\section{MATERIALS AND METHODS}

\section{Patient characteristics and clinical course of disease}

BTL cells were derived from a 51-year-old woman who underwent surgery of glioblastoma within the right frontal lobe at the Department of Neurosurgery, Wagner-Jauregg-Hospital, Linz, Austria. The clinical course of disease and treatment is depicted in Table 1. Post-operative before RT, the patient received one cycle lomustine (CCNU) (100 $\mathrm{mg} \mathrm{m}^{-2}$ body surface area). Radiotherapy started 6 weeks after surgery, but had to be ceased incomplete ( $4000 \mathrm{cgy})$ because of tumour progression. The patient was re-operated 3 months after resection of the primary tumour and afterwards received seven cycles temozolomide $\left(200 \mathrm{mg} \mathrm{day}^{-1}\right.$ $1-5$ every 28 days). After the third cycle, reduction of the tumour bulk was observed by magnetic resonance imaging (MRI), which was confirmed as partial regression after the seventh cycle. Tumour regression was accompanied by continual improvement of performance status. After 8 months, a second recurrence, indicated by sudden worsening of performance status, was confirmed by MRI. Consequently, the patient underwent resurgery 17.5 months after the first relapse but refused further chemotherapy. After 3 months, MRI confirmed tumour progression leading to disease-related death 27 months after initial diagnosis.

Formalin-fixed, paraffin-embedded tissues of primary tumours and recurrences derived from additional five glioblastoma patients (GL1 -5) with recurrent disease were obtained from the Institute of Pathology, Wagner Jauregg Hospital, Linz. Therapy response and overall survival times are depicted in Table 3. All patients gave informed consent.

\section{Establishment of tumour cell cultures}

Primary cell cultures were established from all three surgery specimens (BTL1, BTL2, and BTL3) and were used at passage numbers 5-15 for analysis. Patches from non-necrotic parts of the tumour were obtained during surgery, minced mechanically and transferred into culture flasks, containing growth medium (RPMI $1640,20 \%$ fetal calf serum (FCS), $1 \%$ glutamine, $1 \%$ penicillin/ streptomycine; PAA Laboratories, Linz, Austria). After the third passage, cells were grown in growth medium with 7\% FCS and $1 \%$ glutamine and without antibiotics. Three to five culture flasks were set up from each surgery specimen. Cell cultures were then pooled during the first passages. All cell cultures were periodically checked for Mycoplasma contamination (Mycoplasma Stain Kit; Sigma, St Louis, MO, USA).

\section{Cytogenetic analyses}

Microdissection of paraffin-embedded materials was carried out using the Leica AS LMD Laser Microdissection System (Cambridge, UK). Preparation of genomic DNA was performed as described previously (Pirker et al, 2004). Comparative genomic

Table I Course of disease of the BTL patient

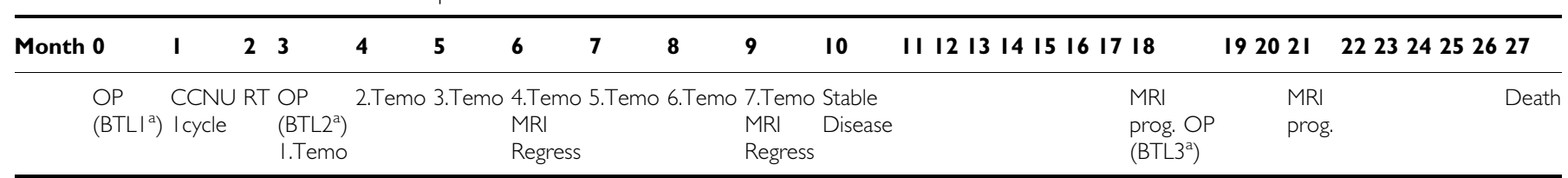

${ }^{a}$ Establishment of the indicated BTL cell cultures from the respective surgery (OP) specimens. CCNU, lomustine; RT, radiotherapy; Temo, temozolomide; prog, tumor progression.

Table 2 Chemosensitivity of the investigated cell lines

Cytotoxicity $\left(\mathrm{IC}_{50}\right)^{\mathrm{a}}$

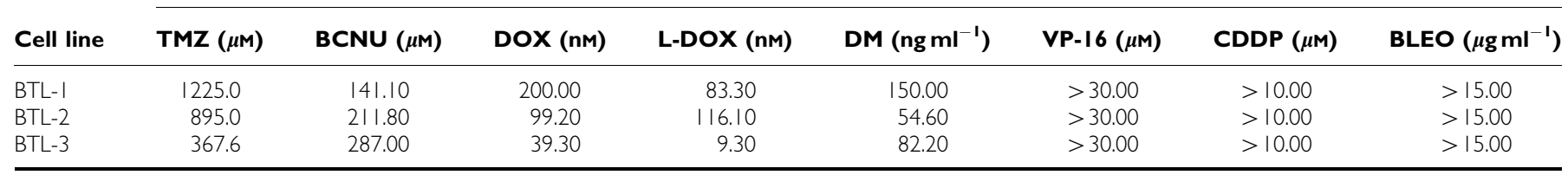

${ }^{a}$ Data are expressed as $I C_{50}$ values (means of three experiments performed in triplicate) of the tested drugs (temozolomide, TMZ, carmustine, BCNU; doxorubicin, DOX; liposomal doxorubicin, L-DOX; daunomycin, DM; etoposide, VP-16; cisplatin, CDDP; bleomycin, BLEO). 
Table 3 Chromosomal changes, therapy sensitivity, and overall survival in glioblastoma primary tumours (PT) and corresponding recurrences (Rec)

\begin{tabular}{|c|c|c|c|c|c|c|c|}
\hline \multirow[b]{2}{*}{ Case } & \multicolumn{3}{|c|}{ Number of changes ${ }^{a}$} & \multicolumn{3}{|c|}{ Response to therapy ${ }^{b}$} & \multirow{2}{*}{$\begin{array}{l}\text { OS } \\
\text { Months }\end{array}$} \\
\hline & PT & $\operatorname{Rec} \mathbf{I}$ & $\operatorname{Rec} 2$ & PT & $\operatorname{Rec} \mathbf{I}$ & $\operatorname{Rec} 2$ & \\
\hline GLI & $9 / 1$ & $12.5 / 2$ & $18 / 3$ & - & - & - & 21 \\
\hline GL2 & $9.3 / 3$ & $12 / 5$ & & - & - & & 17,5 \\
\hline GL3 & $3.7 / 3$ & $17.5 / 2$ & & - & - & & 14.5 \\
\hline GL4 & $24 / 1$ & n.a. ${ }^{c}$ & $|4 /|$ & + & n.t. ${ }^{e}$ & n.t. & 39 \\
\hline GL5 & $5.5 / 2$ & $4.7 / 3$ & & - & + & & $26 \mathrm{a}^{\mathrm{d}}$ \\
\hline BTL & n.a. & n.a. & n.a. & - & + & n.t. & 27 \\
\hline
\end{tabular}

${ }^{a}$ Chromosomal aberrations were determined by CGH and chromosome arms with significant changes counted. Data are given as mean changes/microdissected areas analysed. ' $T$ Therapy of TMZ or CCNU was scored in vivo as + when the patient showed partial response or stable disease. ${ }^{\mathrm{C}}$ Not analysed; ${ }^{\mathrm{d} A l i v e ;}{ }^{\mathrm{e}}$ No therapy.

hybridisation (CGH), fluorescence in situ hybridisation (FISH) and CDD banding were performed as described previously (Pirker et al, 2004). For DNA amplification, linker-adapter PCR was used as described (Pirker et al, 2004). For the detection of the EGFR locus, the BAC clone RP11-339F13 supplied by Pieter De Jong (Oakland, CA, USA) was used.

\section{Growth curves}

A total of $5 \times 10^{4}$ cells well $^{-1}$ were seeded into six-well plates. Every $48 \mathrm{~h}$ cells were collected and counted in $0.2 \%$ trypan blue solution, whereas medium changes were performed for the remaining samples.

\section{Scratch assay}

Cells $\left(2 \times 10^{5}\right.$ well $\left.^{-1}\right)$ were plated in a six-well plate. When the cells had reached about $90 \%$ confluence, the monolayer was wounded by setting an ' $\mathrm{X}$ '-shaped scratch with a sterile plastic tip. Several areas of the scratch were documented by photomicrographs and followed for up to $44 \mathrm{~h}$. The width of the gap was measured at several time points with a Leica TE100 microscope equipped with a CCD camera (Cambridge, UK) and the gap width was measured using Metamorph 6.1 software (Universal Imaging Corp., Biocompare).

\section{Bisulphite modification and MSP}

Methylation-specific PCR (MSP) exploits the effect of sodium bisulphite on DNA, which efficiently converts unmethylated cytosine to uracil but which leaves methylated cytosine unchanged. DNA from cultured cells was extracted with QIAmp DNA Blood Mini Kit (Qiagen, Valencia, CA, USA) and $1 \mu \mathrm{g}$ of genomic DNA was denatured with $\mathrm{NaOH}(3 \mathrm{M})$. Following denaturation, $10 \mathrm{~mm}$ hydrochinone (Sigma) and $3 \mathrm{~m}$ sodium-bisulphite (Sigma) were added and DNA modification was performed at $50^{\circ} \mathrm{C}$ for $16 \mathrm{~h}$. DNA samples were then purified with the Wizard DNA purification resin (Promega, Mannheim, Germany) followed by ethanol precipitation. Methylation-specific PCR was performed with primers specific for either methylated or modified unmethylated DNA, as described previously (Esteller et al, 1999). For PCR a $25 \mu \mathrm{l}$ mix consisting of DNA, specific primers and HotStarTaqMasterMix (1.25 U HotStarTaq DNA Polymerase; $1 \times$ PCR buffer; $100 \mu \mathrm{M}$ of each dNTP; Qiagen) was prepared and amplification was carried out in the iCycler Thermal Cycler (BioRad, Hercules, CA, USA) starting with an initial activation step at $95^{\circ} \mathrm{C}$ for $15 \mathrm{~min}$. Thirtyfive cycles were performed with an annealing temperature of $66^{\circ} \mathrm{C}$. DNA from melanoma metastasis primary cell cultures served as control for methylated as well as unmethylated MGMT promoter. A total of $10 \mu \mathrm{l}$ of each PCR reaction were loaded onto a $6 \%$ polyacrylamide gel and ethidium bromide-stained gels were visualised under UV illumination (ChemiDoc; BioRad). Expression levels were quantified by Quantity One Quantitation software (BioRad) and calculated relatively to the indicated controls.

\section{RT - PCR}

mRNA expression of the chemoresistance-related proteins MGMT, P-gp, MVP, and MRP1 was determined by RT - PCR analysis. Total cellular RNA was extracted and RT-PCR performed with One Step RT-PCR Kit (Qiagen) using oligonucleotide primer sets specific for MGMT (sense $5^{\prime}$-CCTGGCTGAATGCCTATTTC-3'; antisense 5'-CAGCTTCCATAACACCTGTCT-3'; product size: $116 \mathrm{bp}$ ), P-gp (sense 5'-CCCATCATTGCAATAGCAGG-3'; antisense 5'-GTTC AAACTTCTGCTCCTGA-3'; $170 \mathrm{bp}$ ), MVP (sense $5^{\prime}$-TTCTGGAT TTGGTGGACGC- $3^{\prime}$; antisense $5^{\prime}$-MVP antisense $5^{\prime}$-ACTT CTCTCCCTTGACCA-3'; $284 \mathrm{bp}$ ) and MRP1 (sense $5^{\prime}$-GGACCTG GACTTCGTTCTCA-3'; MRP1 antisense 5'-CGTCCAGACTTCTT CATCCG-3'; $291 \mathrm{bp}$ ). GAPDH was amplified (358 bp) as described in (Berger et al, 2000) as a housekeeping gene. For semiquantitative evaluation, 30 cycles were chosen for MGMT, P-gp, MVP, and MRP1 and 22 cycles for GAPDH. Amplification was performed in a thermal cycler (iCycler; Bio-Rad) under the following cycle conditions: $94^{\circ} \mathrm{C}$ for $30 \mathrm{~s} ; 56^{\circ} \mathrm{C}$ for $40 \mathrm{~s} ; 72^{\circ} \mathrm{C}$ for $40 \mathrm{~s}$. Amplification products were separated by acrylamide gel electrophoresis, stained with ethidium bromide and quantified by scanning densitometry (Chemi Doc, Quantity One Quantitation software, Bio-Rad, Hercules, CA, USA). Expression levels (arbitrary units) were calculated relatively to GAPDH mRNA amplified concomitantly.

\section{Western blot}

Protein expression was determined by immunoblot analysis. Total protein extracts (determination of MGMT and MVP) as well as preparation of crude membrane extracts (P-gp, MRP1) were prepared as described previously (Berger et al, 1997; Berger et al, 2000) and protein concentrations measured with BCA Protein Assay (Pierce, Rockford, IL, USA). Proteins were separated by SDS-PAGE and transferred onto nitrocellulose membranes (Hybond ECL, Amersham, Aylesbury, UK). Blots were probed with monoclonal antibodies against MGMT (Dako, Glostrup, Denmark), MVP (Transduction Laboratories, Lexington, KY, USA), P-gp (C219; Centocor, Malvern, PA, USA) and MRP1 (MRPr1; Alexis Biochemicals, San Diego, CA, USA). Visualisation and quantification were performed using the ChemiDoc System (BioRad, Hercules, CA, USA). In previous studies, multiple glioblastoma cell lines established in our laboratory were extensively characterised for their expression of drug resistance genes (Berger et al, 2001; Bredel, 2001; Spiegl-Kreinecker et al, 2002). Respective protein extracts of the following cell lines have been used as positive controls in Western blot analysis: for MGMT GL80, for MVP GL54, for MRP1 GL52 and for P-gp YT-BO.

\section{Chemosensitivity testing}

The impact of the investigated drugs on cell proliferation and viability was tested by establishing whole dose-response curves using an MTT-based survival assay (EZ4U, Easy-for-you, Biomedica, Vienna, Austria). Cells in logarithmic growth phase were seeded in triplicates into three 96 -well plates (3 or $1.5 \times 10^{3} 100 \mu \mathrm{lwell}^{-1}$ ) and incubated for $24 \mathrm{~h}$ at $37^{\circ} \mathrm{C}$. All drugs were applicated for $72 \mathrm{~h}$ or 5 days continuous exposure. The surviving proportions of cells as compared to the untreated controls were determined using EZ4U according to the instructions of the manufacturer. Experiments were repeated three times and $\mathrm{IC}_{50}$ values were calculated from whole dose-response curves.

Additionally, the impact of temozolomide on ${ }^{3} \mathrm{H}$-thymidine incorporation was determined in BTL cells. Cells $\left(4 \times 10^{3}\right.$ per 
$100 \mu \mathrm{lwell}^{-1}$ ) were seeded into a 96-well plate and after $24 \mathrm{~h}$ exposed for $48 \mathrm{~h}$ to $50-1500 \mu \mathrm{m}$ temozolomide. After the exposure culture medium was replaced for $1 \mathrm{~h}$ by a $2 \mathrm{nM}{ }^{3} \mathrm{H}$-thymidine solution (diluted in full culture medium, radioactivity: $\left.25 \mathrm{Ci} \mathrm{m}^{-1}\right)$. Afterwards cells were washed three times with PBS, cell lysates prepared and radioactivity was determined as described (Berger et al, 1994). Experiments were carried out in triplicates and results (means of two experiments) are expressed relatively to the untreated controls set arbitrarily as 1 .

In order to determine the cytotoxic activity of temozolomide, Hoechst 33258/propidium iodide (PI) co-staining (both from Sigma) to determine the number of viable and apoptotic/dead cells was performed as described (Grusch et al, 2001). Cells in logarithmic growth phase were seeded in triplicates into 96-well plates $\left(1 \times 10^{3}\right.$ per $\left.100 \mu \mathrm{lwell}^{-1}\right)$ and incubated for $24 \mathrm{~h}$ at $37^{\circ} \mathrm{C}$. Temozolomide was applicated for 5 days of continuous exposure. Hoechst 33258 and PI were added directly to the culture medium to final concentrations of 5 and $2 \mu \mathrm{g} \mathrm{ml}^{-1}$, respectively. After an incubation period of $1 \mathrm{~h}$ at $37^{\circ} \mathrm{C}$ the cells were examined on a Zeiss Axiovert 35 fluorescence microscope with DAPI filters, and viable (Hoechst-positive, PI-negative) and dead (Hoechst-positive, PIpositive)/apoptotic (Hoechst-positive with condensed/fragmented chromatin, PI-negative) cells were counted.

\section{Drugs}

Temozolomide and liposomal doxorubicin (L-DOX) were kindly provided by AESCA Pharma (Traiskirchen, Austria). All other drugs used were obtained from Sigma (St Louis, MO, USA).

Cytotoxic effects were analysed for daunomycin $(9-180 \mathrm{nM})$, etoposide (VP16; 0.5-25 $\mu \mathrm{M}$ ), cisplatin (CDDP; 0.25-5 $\mu \mathrm{M}$ ), doxorubicin (DOX; 10-150 nM), L-DOX (10-150 nM), bleomycin (BLEO 1-100 $\mathrm{mU} \mathrm{ml}^{-1}$ ), carmustine (BCNU; 50-600 $\mu \mathrm{M}$ ), and temozolomide (TMZ 100-1500 $\mu \mathrm{M})$. Drugs were dissolved in physiological saline (DM, DOX), DMSO (VP16, TMZ), ethanol (BCNU), and aqua bidest (BLEO, CDDP). L-DOX was provided as sterile solution ready for use.

\section{RESULTS} Cytogenetic analyses of BTL1-3 cells show changes typical
for glioblastoma multiforme

Three cell lines termed BTL1, BTL2, and BTL3 were established from consecutive surgeries of a primary tumour and two recurrences of a long-term surviving glioblastoma patient. The respective course of disease, therapies, and the time points of surgery are summarised in Table 1 . Chromosomal changes in the cell lines were analysed by $\mathrm{CGH}$ and classical cytogenetics. Figure $1 \mathrm{~A}-\mathrm{C}$ present the $\mathrm{CGH}$ profiles of all three cell cultures. The primary tumour-derived cell line BTL1 contained chromosomal changes typical for glioblastoma, for example, gain of chromosome 7 , loss of $9 \mathrm{p}$, as well as loss of chromosome 10 (indicated by arrows in Figure 1A). A respective CGH metaphase for BTL1 is given in Figure 2A. BTL2 cells, derived from the first recurrence progressing during RT and chemotherapy, showed numerous additional chromosomal changes as compared to BTL1 (asterisks in Figure 1B). Some of these aberrations (losses at chromosomes 2, 6q, and 12q) reached only borderline significance in BTL1 and were distinctly more pronounced in BTL2, whereas other changes (gains at chromosomes 14,17p, and 20, losses at chromosomes $17 \mathrm{q}$ and 18 ) were completely new in BTL2. This increase in genomic aberrations reflects a high degree of chromosomal instability of BTL2 cells. Unexpectedly, CGH analysis of BTL3 cells, derived from a second recurrence resected 15 months later, revealed a less aberrant chromosomal pattern with loss of most changes present in BTL2 (a remaining change is shown as asterisk in Figure 1C) and only very few new changes (crosses in Figure 1C). Interestingly, chromosome 7 amplifications present in BTL1 and BTL2 were completely lost in BTL3 cells. Conventional cytogenetics (Figure 2D-F), as well as FISH analysis of BTL cells (Figure 2B and C), widely confirmed the results obtained by CGH. The CDD banding of tumour metaphase chromosomes revealed the existence of at least two different subclones in BTL1 cells. The predominant subclone showed a highly aberrant, nearly tetraploid karyotype with additional copies of chromosome 7 (Figure 2D), whereas the second subclone displayed a less aberrant, nearly diploid karyotype with only two copies of chromosome 7 (Figure 2E). FISH analysis with chromosome paint for chromosome 7 and a specific BAC clone against the EGFR gene locus confirmed these results (Figure 2B). The highly aberrant and instable karyotype of BTL2 cells was confirmed by CDD banding and FISH (data not shown). CDD banding as well as FISH data for BTL3 revealed a mainly triploid karyotype and, corresponding with $\mathrm{CGH}$ results, three copies of chromosome 7 (Figure $2 \mathrm{C}$ and $\mathrm{F}$ ).

\section{CGH analyses of glioblastoma multiforme primary tumours and recurrences}

In addition to the BTL cell model, paraffin-derived materials from the primary tumour and one or two recurrences of five further glioblastoma patients were available for analysis. The numbers of chromosomal changes in these tumour samples were compared to chemotherapy responses and overall survival (Table 3). Tumours of patients GL1, GL2, and GL3 showed increased chromosomal aberrations during disease progression, therapy resistance, and relatively short overall survival (mean of 17.67 months). In contrast, patients GL4 and GL5 displayed distinctly reduced chromosomal instability and in case of GL5 therapy sensitivity in recurrent tumour thus resembling the in vitro BTL cell model. Interestingly, all three respective patients showed remarkable long overall survival (mean of 33 months, patient GL5 still alive at 26 months) although GL4 had refused chemotherapy at recurrence. These observations again indicate that chemosensitive glioblastoma patients may relapse with a less aggressive tumour subclone corresponding to long-term patient survival.

\section{Growth and migration potential}

In parallel to the chromosomal changes, several determinants of tumour cell malignancy were analysed in BTL cells. In vitro cell growth potentials were analysed by establishment of growth curves (Figure 3). Whereas the primary tumour-derived BTL1 cells were relatively slow-growing, BTL2 cells showed significantly increased growth potential especially at enhanced cell density. In contrast, BTL3 cells displayed reduced cell proliferation as compared to BTL2 and trended to enter plateau stage at higher density.

Additional to cell growth, the migratory potential of all BTL cell lines was assessed by monolayer scratch assays. Figure 4A shows photomicrographs of representative scratches in BTL cell monolayers immediately after wounding and following $20 \mathrm{~h}$ of incubation. Figure $4 \mathrm{~B}$ summarises graphically the results from several analysed time points. Although BTL3 cells had completely closed the wound already within $20 \mathrm{~h}$, for both BTL1 and BTL3 the scratch was still visible even after $44 \mathrm{~h}$ of incubation. At these late time points, the parental BTL1 cell line exhibited a slightly higher migratory potential as compared to the second recurrence-derived BTL 3 cells that were unable to close the wound even by $72 \mathrm{~h}$ (data not shown).

\section{Sensitivity against chemotherapeutic interventions}

Chemosensitivity of BTL cell lines against several anticancer agents was established by MTT-based survival assays (Table 2). Using a 


\section{A}
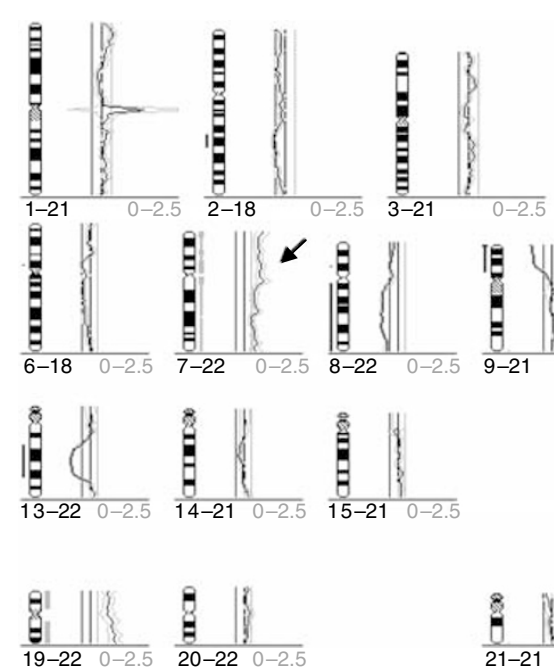

B
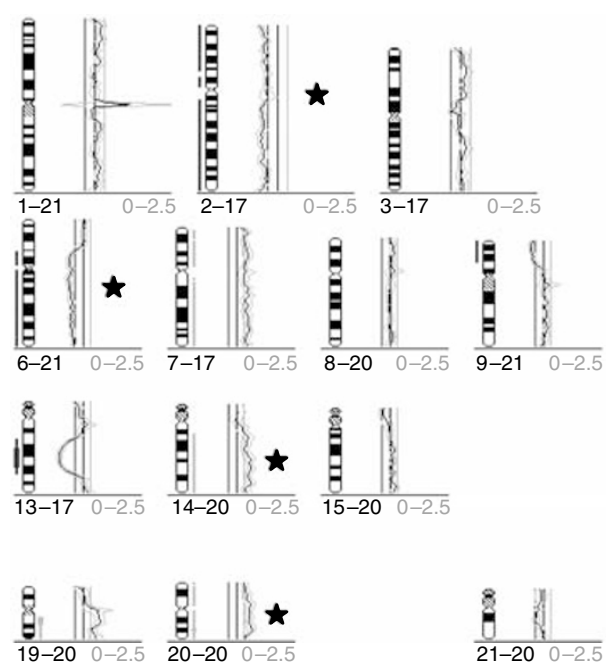

C
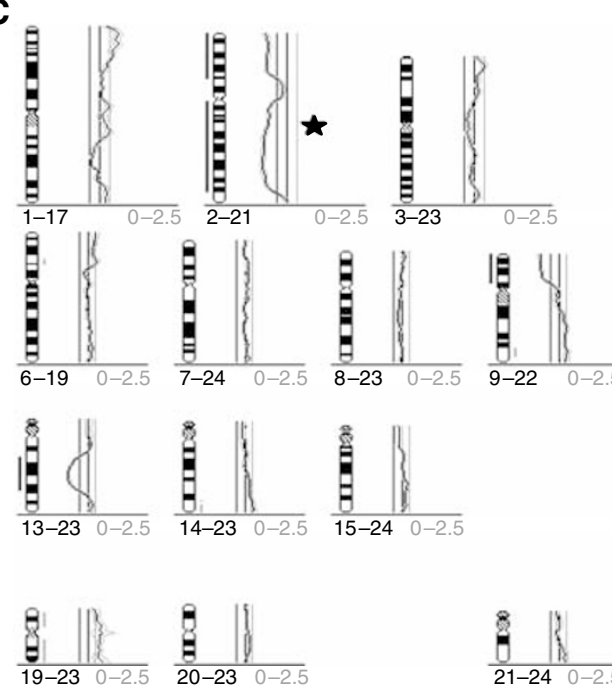
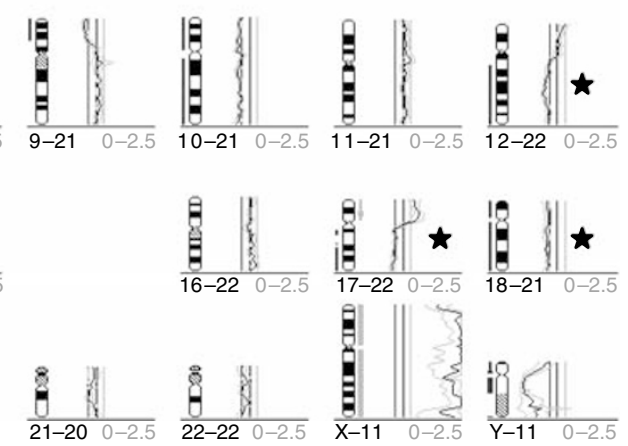

BTL3
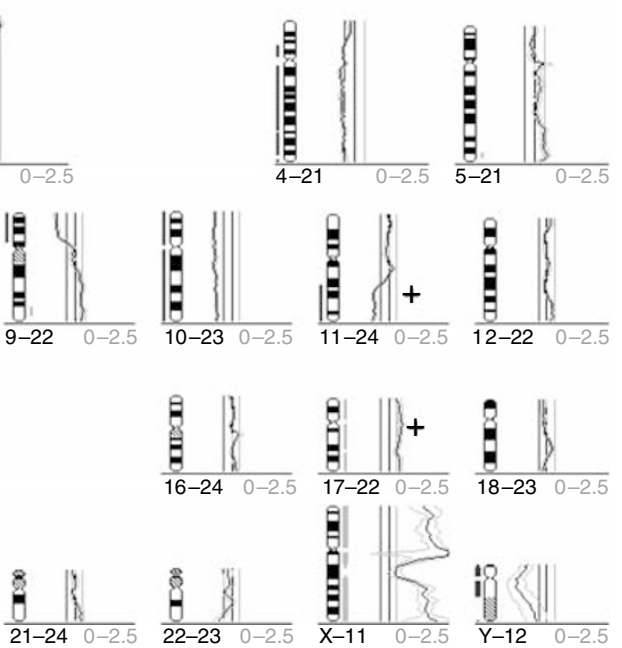

Figure I CGH analysis profiles (for interpretation see Pirker et al, 2003) of (A) primary tumour-derived BTLI, (B) first recurrence-derived BTL2, and (C) second recurrence-derived BTL3 cells. Arrows in (A) indicate typical changes for glioblastoma multiforme. Asterisks in (B) indicate additional chromosomal aberrations in BTL2 as compared to BTLI. In (C) the asterisk indicates an aberration present also in BTL2 but not BTLI. Crosses in (C) represent changes unique to BTL3. 

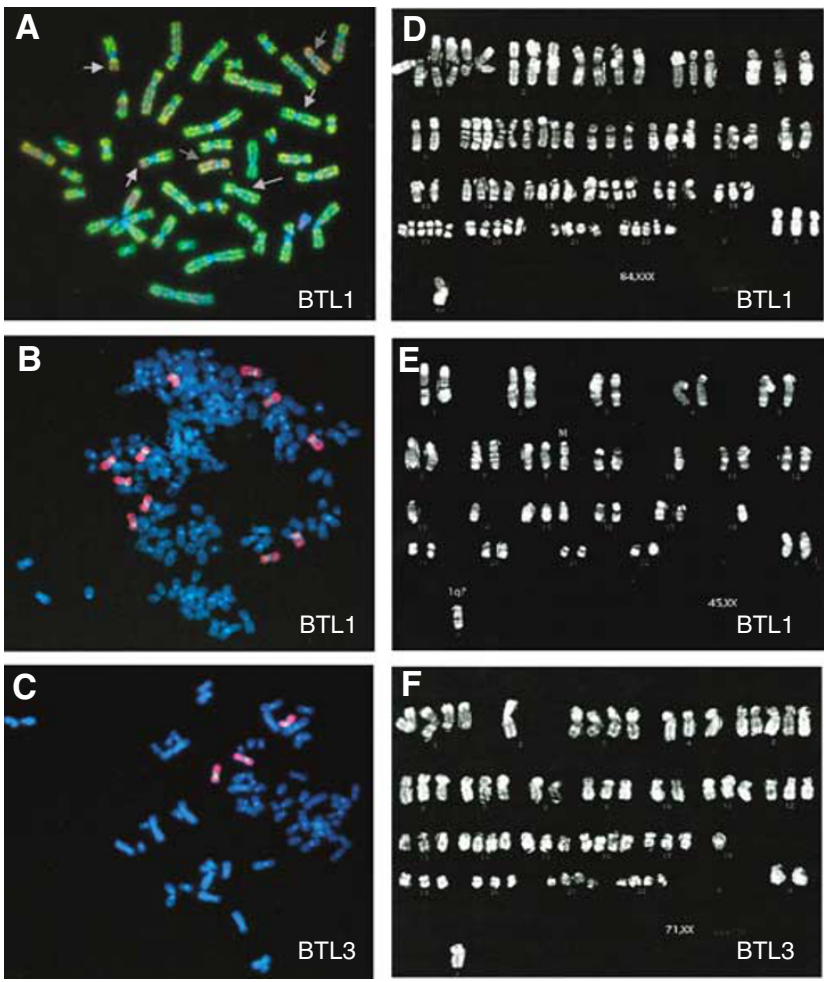

Figure 2 Cytogenetic analysis of the BTL glioblastoma cell model. Representative CGH (A), FISH (B, C), and CDD banding (D-F) analyses of the indicated cell lines are shown. Arrows in $(\mathbf{A})$ indicate typical changes for glioblastoma multiforme. For FISH analysis (B, C) a paint for whole chromosome 7 (red) and a BAC clone for the EGFR locus (green) were used. ( $\mathbf{D}$ and $\mathbf{E}$ ) show representative karyograms of the two subclones detected in BTLI.

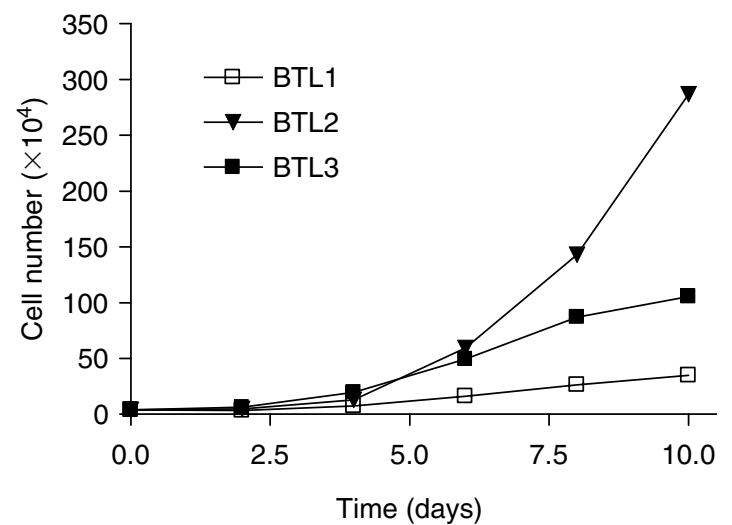

Figure 3 In vitro growth dynamics of the BTL glioblastoma cell model. Growth curves for the indicated cell lines were established as described in Material and Methods. One of three experiments with comparable results is shown.

$72 \mathrm{~h}$ drug exposure, an increasing sensitivity against temozolomide within the BTL cell model was detected by the vitality assay. Thus, BTL3 cells, derived from a recurrence 9 months after successful temozolomide treatment (compare Table 1), exhibited the highest temozolomide sensitivity. With respect to a $72 \mathrm{~h}$ continuous drug exposure, activity of the second alkylating agent BCNU revealed an opposite resistance pattern with the lowest $\mathrm{IC}_{50}$ value in BTL1 cells. Resembling temozolomide, also, the sensitivity against anthracyclines tended to be enhanced in the recurrence-derived sublines with the strongest differences observed in case of doxorubicin.
As characteristic of glioblastoma cells (Bredel, 2001), all BTL sublines were resistant against VP-16, bleomycin, and CDDP. Extending the exposure time in the case of temozolomide to 5 days confirmed the lowest temozolomide sensitivity for the primary tumour -derived cell line BTL1 $\left(\mathrm{IC}_{50}: 605.8 \mu \mathrm{M}\right.$ ), whereas at that exposure time BTL2 cells showed the highest treatment response $\left(\mathrm{IC}_{50}: 158.3 \mu \mathrm{M}\right)$. The higher temozolomide sensitivity of BTL2 cells with increasing exposure time might be explained by the enhanced proliferation of this cell line at higher densities (compare Figure 3). To test this hypothesis, we analysed the impact of a $48 \mathrm{~h}$ temozolomide exposure on DNA synthesis of BTL cells seeded at enhanced density by ${ }^{3} \mathrm{H}$-thymidine incorporation (Figure $5 \mathrm{~A}$ ). Indeed, temozolomide treatment reduced DNA synthesis of BTL2 cells significantly stronger as compared with BTL3, whereas BTL1 cells showed the weakest response. In order to explain the higher temozolomide sensitivity of BTL3 cells in the $72 \mathrm{~h}$ survival assay (compare Table 2), we additionally analysed the cytotoxicity of temozolomide against BTL cells at a 5-days exposure time (Figure 5B). Both recurrence-derived cell lines demonstrated a significantly enhanced percentage of apoptotic/dead cells as compared to parental BTL1 cells with BTL3 showing the highest response to the cytotoxic impact of temozolomide.

\section{Gene expression of chemoresistance-related proteins}

Expressions of the DNA repair enzyme MGMT as well as the chemotherapy resistance markers P-gp, encoded by the mdr1 gene, MRP1, and MVP were detected by RT-PCR (Figure 6A) and Western blots (Figure 6B). All the three cell lines lacked MGMT mRNA and protein expression. Correspondingly, methylation of the MGMT gene promoter was persistently detected in all three cell lines (Figure 6C). Only very low amounts of mdr1 mRNA were detectable by RT-PCR in BTL1 cells, which was even decreasing from BTL2 to BTL3 (Figure 6B). In contrast, P-gp expression was under the detection limit in all three sublines (data not shown). Whereas MRP1 expression was constantly expressed in all cell lines, MVP levels decreased continuously during disease progression.

\section{DISCUSSION}

Multiple genetic alterations are generally found in solid tumours and an increasing complexity of chromosomal aberrations is typically associated with tumour progression (Albertson et al, 2003). This implies that chromosomal instability can act as a driving force for tumorigenesis, leading to tumour cell immortalisation and the acquisition of new subclones with features of enhanced aggressiveness. Based on the assumption that gliomas are clonal tumours (Bonneau and Longy, 2000), both shared genetic changes as well as the appearance of additional alterations during disease progression are expected to be found in glioblastomas and their recurrences (Fujisawa et al, 1999; Saxena et al, 1999). Similarly, acquisition of therapy resistance is believed to depend on the selection of subclones exhibiting activation of the respective resistance mechanisms (Bredel, 2001). In this study, we have analysed the dynamics of chromosomal instability and chemosensitivity during glioblastoma progression using a unique cell model comprising three cell lines derived from surgery specimens of a long-term surviving glioblastoma patient. Cell cultures were obtained from the primary tumour before therapy and two consecutive recurrences resected during and 9 months after termination of RT- and/or chemotherapy, respectively (Table 1). The cell biological analyses of these cell models argue against the hypothesis of a linear increase of tumour aggressiveness and therapy resistance during disease progression and reveal that even late glioblastoma recurrences can represent relatively inaggressive and highly chemosensitive tumour cell subclones. 


\section{A}

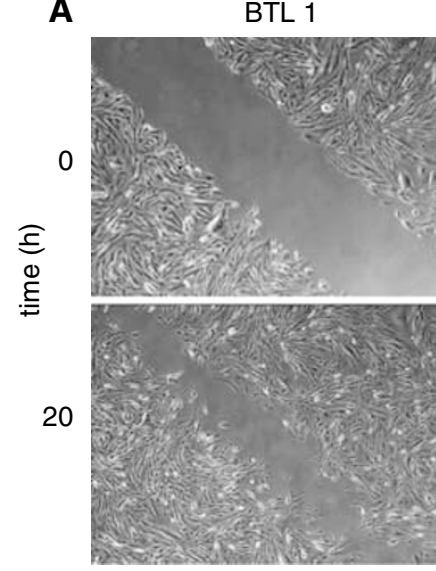

BTL 2

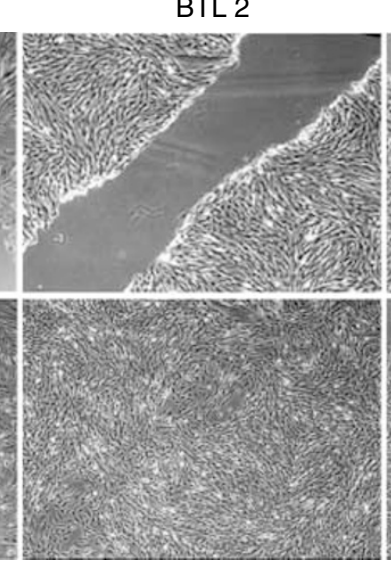

BTL 3

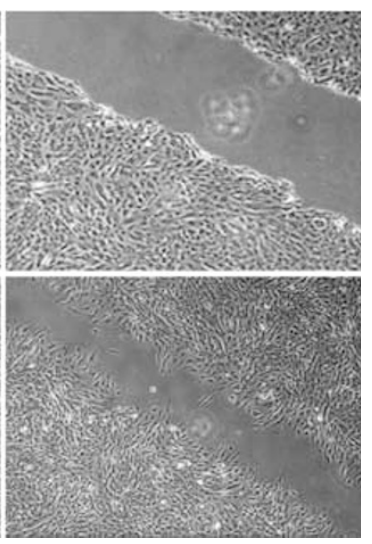

B

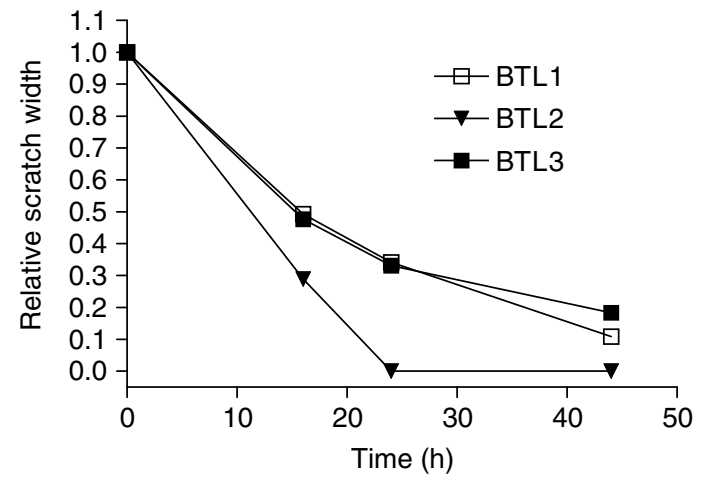

Figure 4 Migratory potential of the BTL glioblastoma cell model. Scratch assays were performed as described in Materials and Methods. (A) Representative photomicrographs taken at the indicated time points are shown. (B) To determine the relative closure of the gap, photomicrographs as shown in (A) were taken at different time points and measured using MetaMorph 6.I software. The gaps' widths immediately after wounding were arbitrarily set as I. At least three experiments with comparable results were performed.

Although these data are derived from only one cell model, the respective conclusions were also corroborated by the analysis of paraffin-embedded material obtained from primary tumours together with the corresponding recurrences of five additional glioblastoma patients. Although in the three therapy-resistant cases chromosomal aberrations increased during disease progression, two patients developed a recurrence with a less aberrant genotype. Paralleling the BTL cell model, one of these patients (GL5) responded to chemotherapy after relapse, whereas the other patient (GL4) unfortunately refused further chemotherapy. All three patients recurring with less aberrant genotypes showed a remarkably long survival time. These data point towards general differences in the dynamics of chromosomal instability and chemosensitivity in short- and long-term surviving glioblastoma patients. However, it has to be kept in mind that the current study only involves one cell model and five additional glioblastoma patients. Thus, further studies, including extended patient numbers and, if possible, further cell models, are necessary to confirm our observations.

Intratumoral heterogeneity of glioblastoma multiforme has been mostly described with regard to histopathological features; however, also the presence of genetically different cell clones in glioblastoma at diagnosis has been occasionally reported (Hulsebos et al, 2004). Correspondingly, cytogenetic analysis of our primary tumor-derived BTL1 cell line demonstrated the presence of at least two cell subclones with different chromosomal aberrations. Although one of them exhibited strong chromosomal instability and alterations associated with high aggressiveness, CDD banding revealed the existence of a second, less rearranged and nearly diploid subclone. Interestingly, these subclones resembled in several aspects those cell lines established from the first and second recurrence, namely BTL2 and BTL3 cells, respectively.

In $\mathrm{CGH}$ analysis, the primary tumor- and the first recurrencederived cell lines BTL1 and BTL2 exhibited several alterations characteristic of highly malignant gliomas, including loss of chromosome $10 \mathrm{q}$, with the PTEN and the MGMT gene locus on 10q23.3 and 10q26, respectively, loss of material from chromosome $9 \mathrm{p}$, with the CDKN2A locus on 9p16, and gain of chromosome 7 resulting in amplifications at the epidermal growth factor receptor (EGFR) locus on $7 \mathrm{p} 12$ (Inda et al, 2003). Interestingly, CGH and FISH analyses revealed that BTL3, the second recurrence-derived cell line, harboured neither any gains of chromosome 7 nor additional EGFR copy numbers. Moreover, BTL3 cells demonstrated reduced proliferative and migratory potential. This suggests loss of several features of glioblastoma aggressiveness in BTL3 probably based on lower EGFR-mediated signals (Aghi et al, 2005; Kang et al, 2005; Lamszus et al, 2005). Loss of chromosome 7 copy numbers was also observed in the recurrent tumour of GL5, showing only a borderline gain of chromosome 7 , whereas the primary tumour displayed chromosome 7 amplification (data not shown). Accordingly, EGFR amplification has been shown to be a negative prognostic factor for overall survival of glioblastoma patients and to correlate with shorter time to tumour progression (Schlegel et al, 1994a, b; Zhu et al, 1996; Etienne et al, 1998). Also gain of chromosome 7 together with loss of chromosome 10, the most frequently found combined genetic alterations in glioblastomas, are associated with poor prognosis and short survival (Wiltshire et al, 2000; Ohgaki et al, 2004; Nigro et al, 2005). 

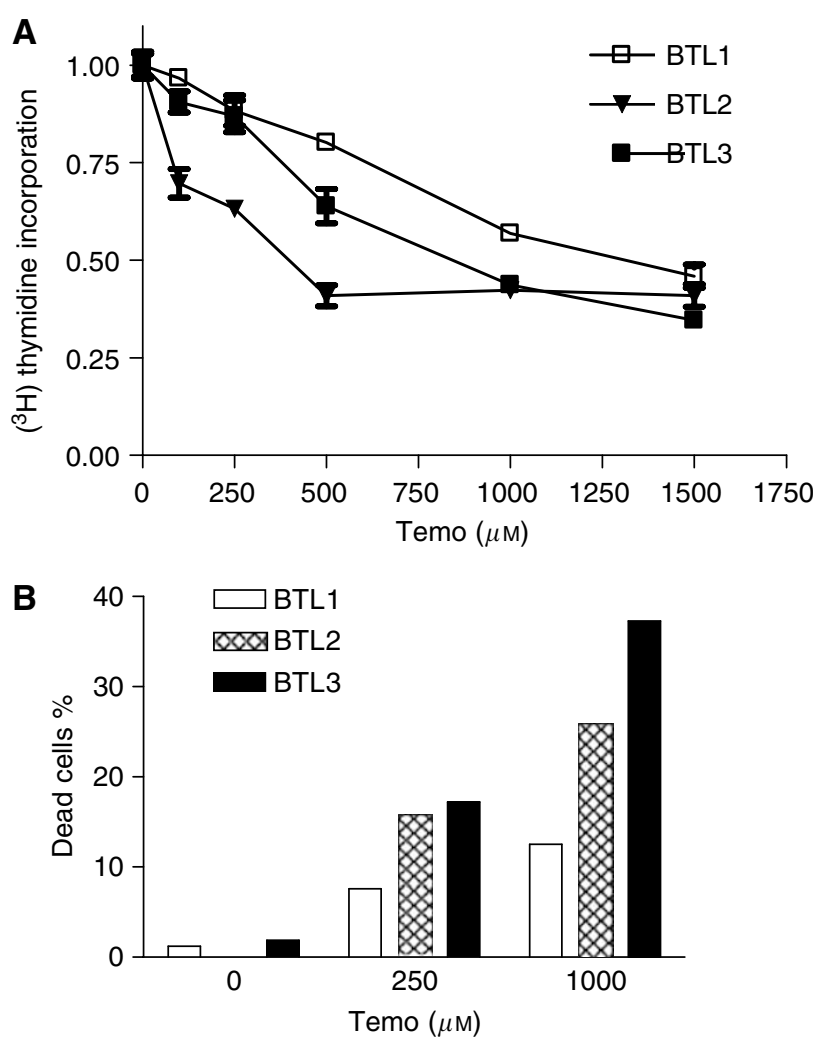

Figure 5 Antiproliferative and cytotoxic effects of temozolomide against BTL cells. (A) The indicated BTL cell lines were exposed to increasing temozolomide concentrations for $48 \mathrm{~h}$ and the rate of DNA synthesis was determined by ${ }^{3} \mathrm{H}$-thymidine incorporation. Data are given relatively to the untreated controls set as I. Means of two experiments in triplicates are shown. (B) BTL cells were exposed for 5 days to the indicated temozolomide concentrations and the percentage of apoptotic/dead cells was determined by Hoechst 33258 and PI staining as described in Materials and Methods. One representative example out of three experiments delivering comparable results is shown.

With respect to BTL2 cells, the cytogenetic data suggest that the first recurrence is derived from the more aggressive subclone of the primary tumour, which might be reflected by chromosomal changes that are borderline in BTL1 but reach significance in BTL2 (losses in chromosomes 2, 6q, and 12q). The additional new changes in BTL2 might be caused by DNA damage based on proliferation under RT and chemotherapy. However, the enhanced growth and migration potential in BTL2 as compared to BTL1 suggests that the observed differences might also reflect directed malignant progression. In contrast, the surprisingly low aggressiveness of BTL3 cells together with a comparable subclone in BTL1 cells suggest that dormant tumour cells from this or a comparable BTL1 subclone could have evaded the two surgeries as well as RT and chemotherapy. Correspondingly, Schmidt-Kittler et al (2003) have reported an early dissemination of single breast cancer cells with different chromosomal aberrations from the primary tumour to the surrounding healthy tissue. Absence of several alterations detected in the primary tumour suggested dissemination not only from the most advanced clone but also from pre-stages before immortalisation (Schmidt-Kittler et al, 2003). Alternatively, one might hypothesise that BTL3 is not derived from BTL1 but represents a second unrelated metachronous glioblastoma as has been reported before (Inda et al, 2003). However, several shared chromosomal alterations both in BTL cell lines as well as in the paired, paraffin-embedded tissue samples analysed (data not shown) strongly suggest in all cases derivation
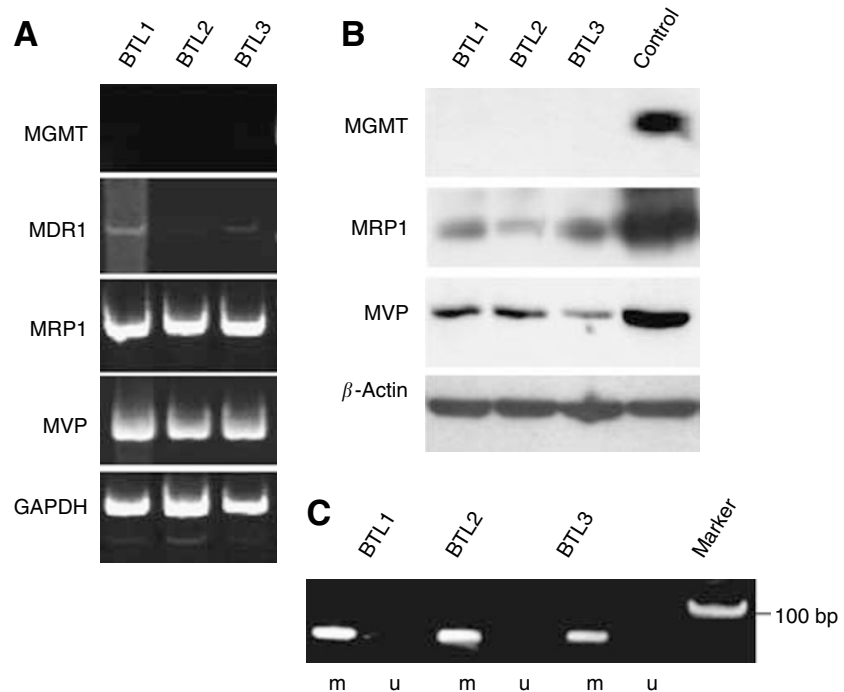

Figure 6 Expression of chemoresistance-related genes in BTL glioblastoma cells. mRNA $(\mathbf{A})$ and protein $(\mathbf{B})$ levels encoded by the indicated chemoresistance genes were determined by RT-PCR and Western blot, respectively. (C) Methylation of the MGMT promoter was detected by methylation-specific PCR and a representative experiment is shown ( $\mathrm{m}=$ methylated; $\mathrm{u}=$ unmethylated). Protein extracts of the glioblastoma cell lines GL80, GL54, and GL52 were used as positive controls for MGMT, MVP, and MRPI, respectively.

from a single founder clone that has developed to several genetically different subclones during tumour progression.

The first recurrence, represented by BTL2 cells, developed after ineffective chemotherapy and under RT. Consequently, one would expect enhanced chemoresistance of this and all following recurrences. Indeed, we detected moderately reduced sensitivity after a $72 \mathrm{~h}$ exposure of both BTL2 and BTL3 cells against the nitrosourea $\mathrm{BCNU}$ in vitro. To our surprise, the sensitivity against temozolomide, another alkylating agent, followed an inverse pattern revealing a continuous increase in temozolomide sensitivity from the primary tumour to the second recurrence. This was based on enhanced cytotoxic activity of temozolomide in both recurrence-derived cell lines with a particularly high cell death rate in BTL3 cells. At longer exposure times and higher cell density, BTL2 cells displayed the highest temozolomide-induced proliferation arrest, probably based on the more aggressive growth behaviour of these cells. Correspondingly, the patient responded to monotherapy with this agent after the first relapse. This might implicate that temozolomide as a strong mutagen in the absence of MGMT activity (Rabik et al, 2006) might have selected the less aggressive BTL3 cell subclone by preferentially killing the highly proliferative and not density-arrested BTL2 cell population. This is especially notable as temozolomide treatment was recently shown to significantly prolong overall survival of glioblastoma patients (Stupp et al., 2005) and thus has largely replaced nitrosoureas in the treatment of glioma (van den Bent et al, 2006).

With respect to temozolomide response, expression of the repair enzyme MGMT was suggested as the major resistance factor (Gerson, 2002) and lack of MGMT expression in gliomas is mainly based on gene promoter methylation (Silber et al, 1998; Esteller et al, 1999, 2000). Recently, promoter methylation was shown to represent an independent prognostic factor in glioblastoma patients (Hegi et al, 2005) and to be associated with enhanced overall survival after treatment with RT/temozolomide (Hegi et al, 2004). In our cell model, a persistent methylation of the MGMT gene promoter, even after application of temozolomide, has been detected in all three BTL cell lines, resulting in a complete lack of MGMT protein expression. Correspondingly, all BTL cell lines 
were sensitive to temozolomide, however, to a markedly different extent. Moreover, in the $72 \mathrm{~h}$ exposure vitality assay an inverse correlation of $\mathrm{BCNU}$ and temozolomide responsiveness was surprisingly observed. However, it has to be mentioned that at long BCNU exposure times ( 5 days), $\mathrm{IC}_{50}$ values for all three BTL cell lines averaged out at about $60-80 \mu \mathrm{M}$ (data not shown) whereas differences in case of temozolomide still were highly significant. As all three BTL sublines did not express MGMT, other resistance factors must underlie these observations. It has to be kept in mind that BCNU and $\mathrm{CCNU}$, as chloroethylating agents, induce intra- and interstrand DNA crosslinks, whereas methylating agents, like temozolomide, primarily lead to $\mathrm{O}^{6}$-methylguanine adducts (Aquilina et al, 1994). Several recent observations suggest that resistance of glioblastomas to alkylating agents seems to follow a more complex pattern than simple dependence on MGMT levels. Thus, for example, the cellular p53 status and consequently inducibility of p21 by alkylating agents (Bocangel et al, 2002) as well as the base-excision repair capacity (Trivedi et al, 2005) were shown to influence alkylating agent response. Moreover, cells with mutated mismatch repair genes were particularly resistant to temozolomide, but not to chloroethylating agents (Gerson, 2002; Liu et al, 1996). In addition to repair mechanisms, also signals regulating cell death and survival pathways were implicated to regulate temozolomide response (Bredel et al, 2006)

When comparing alkylating agents with several other chemotherapeutics, an increased response in the recurrence-derived BTL cell lines was also observed in anthracyclines, whereas all cells were persistently unresponsive to VP-16, CDDP, and bleomycin. Highintrinsic chemoresistance of glioma cells has been reported by us and other groups involving overexpression of known drugresistance proteins like P-gp, MRP1, and MVP (Berger et al,
2001; Bredel, 2001; Spiegl-Kreinecker et al, 2002). In our cell model, we found very low levels of mdr1 mRNA without detectable P-gp, persistent expression of MRP1, and reduction of MVP expression especially in BTL3 cells. In a previous study, we observed correlation between MVP expression of glioblastoma cells and resistance to anthracyclines (Berger et al, 2001), which suggests a contribution of MVP at least to doxorubicin hypersensitivity of BTL3 cells. Additionally, EGFR-transmitted signals are known to contribute to apoptosis resistance of glioblastoma cells (Shinojima et al, 2003) leading, for example, to CDDP insensitivity (Nagane et al, 1998). Moreover, response of xenografted gliomas to different alkylating agents was attenuated by EGFR amplification (Leuraud et al, 2004). Thus, the loss of EGFR amplification in BTL3 cells might also contribute to reduced chemoresistance.

From the clinical point of view, our data, although derived from only one cell model and a very limited number of cases, corroborate several clinical reports that have demonstrated activity of temozolomide in patients with recurring astrocytic brain tumours (for review see van den Bent et al, 2006). For example, a recent study reported a $43 \%$ response rate for salvage therapy with temozolomide for prior temozolomide responders at recurrence (Franceschi et al, 2005). In conclusion, we suggest that application of temozolomide represents a feasible strategy for glioblastoma treatment especially in patients with methylated MGMT promoter even at repeated recurrence and following chemo- and/or RT.

\section{ACKNOWLEDGEMENTS}

We thank Gabriele Reisinger and Barbara Stögermayer for skilful technical assistance.

\section{REFERENCES}

Aghi M, Gaviani P, Henson JW, Batchelor TT, Louis DN, Barker II FG (2005) Magnetic resonance imaging characteristics predict epidermal growth factor receptor amplification status in glioblastoma. Clin Cancer Res 11: $8600-8605$

Albertson DG, Collins C, McCormick F, Gray JW (2003) Chromosome aberrations in solid tumors. Nat Genet 34: 369-376

Aquilina G, Hess P, Branch P, MacGeoch C, Casciano I, Karran P, Bignami M (1994) A mismatch recognition defect in colon carcinoma confers DNA microsatellite instability and a mutator phenotype. Proc Natl Acad Sci USA 91: 8905-8909

Berger W, Elbling L, Hauptmann E, Micksche M (1997) Expression of the multidrug resistance-associated protein (MRP) and chemoresistance of human non-small-cell lung cancer cells. Int J Cancer 73: 84-93

Berger W, Elbling L, Micksche M (2000) Expression of the major vault protein LRP in human non-small-cell lung cancer cells: activation by short-term exposure to antineoplastic drugs. Int J Cancer 88: 293 - 300

Berger W, Elbling L, Minai-Pour M, Vetterlein M, Pirker R, Kokoschka EM, Micksche M (1994) Intrinsic MDR-1 gene and P-glycoprotein expression in human melanoma cell lines. Int J Cancer 59: 717-723

Berger W, Spiegl-Kreinecker S, Buchroithner J, Elbling L, Pirker C, Fischer J, Micksche M (2001) Overexpression of the human major vault protein in astrocytic brain tumor cells. Int J Cancer 94: 377-382

Bocangel DB, Finkelstein S, Schold SC, Bhakat KK, Mitra S, Kokkinakis DM (2002) Multifaceted resistance of gliomas to temozolomide. Clin Cancer Res 8: $2725-2734$

Bonneau D, Longy M (2000) Mutations of the human PTEN gene. Hum Mutat 16: 109-122

Bredel M (2001) Anticancer drug resistance in primary human brain tumors. Brain Res Brain Res Rev 35: $161-204$

Bredel M, Bredel C, Juric D, Duran GE, Yu RX, Harsh GR, Vogel H, Recht LD, Scheck AC, Sikic BI (2006) Tumor necrosis factor-alpha-induced protein 3 as a putative regulator of nuclear factor-kappaB-mediated resistance to 06 -alkylating agents in human glioblastomas. J Clin Oncol 24: $274-287$
Buckner JC (2003) Factors influencing survival in high-grade gliomas Semin Oncol 30: $10-14$

DeAngelis LM (2003) Benefits of adjuvant chemotherapy in high-grade gliomas. Semin Oncol 30: 15-18

Duerr EM, Rollbrocker B, Hayashi Y, Peters N, Meyer-Puttlitz B, Louis DN, Schramm J, Wiestler OD, Parsons R, Eng C, von Deimling A (1998) PTEN mutations in gliomas and glioneuronal tumors. Oncogene 16: 2259- 2264

Esteller M, Garcia-Foncillas J, Andion E, Goodman SN, Hidalgo OF, Vanaclocha V, Baylin SB, Herman JG (2000) Inactivation of the DNArepair gene MGMT and the clinical response of gliomas to alkylating agents. New Engl J Med 343: $1350-1354$

Esteller M, Hamilton SR, Burger PC, Baylin SB, Herman JG (1999) Inactivation of the DNA repair gene O6-methylguanine-DNA methyltransferase by promoter hypermethylation is a common event in primary human neoplasia. Cancer Res 59: $793-797$

Etienne MC, Formento JL, Lebrun-Frenay C, Gioanni J, Chatel M, Paquis P, Bernard C, Courdi A, Bensadoun RJ, Pignol JP, Francoual M, Grellier P, Frenay M, Milano G (1998) Epidermal growth factor receptor and labeling index are independent prognostic factors in glial tumor outcome. Clin Cancer Res 4: 2383-2390

Franceschi E, Omuro AM, Lassman AB, Demopoulos A, Nolan C, Abrey LE (2005) Salvage temozolomide for prior temozolomide responders. Cancer 104: $2473-2476$

Fujisawa H, Kurrer M, Reis RM, Yonekawa Y, Kleihues P, Ohgaki H (1999) Acquisition of the glioblastoma phenotype during astrocytoma progression is associated with loss of heterozygosity on 10q25-qter. Am J Pathol 155: $387-394$

Gerson SL (2002) Clinical relevance of MGMT in the treatment of cancer. J Clin Oncol 20: 2388-2399

Grusch M, Fritzer-Szekeres M, Fuhrmann G, Rosenberger G, Luxbacher C, Elford HL, Smid K, Peters GJ, Szekeres T, Krupitza G (2001) Activation of caspases and induction of apoptosis by novel ribonucleotide reductase inhibitors amidox and didox. Exp Hematol 29: 623-632 
Harris LC, Margison GP (1993) Expression in mammalian cells of the Escherichia coli 06 alkylguanine-DNA-alkyltransferase gene ogt reduces the toxicity of alkylnitrosoureas. Br J Cancer 67: 1196-1202

Hegi ME, Diserens AC, Godard S, Dietrich PY, Regli L, Ostermann S, Otten P, Van Melle G, de Tribolet N, Stupp R (2004) Clinical trial substantiates the predictive value of $O$-6-methylguanine-DNA methyltransferase promoter methylation in glioblastoma patients treated with temozolomide. Clin Cancer Res 10: 1871 - 1874

Hegi ME, Diserens AC, Gorlia T, Hamou MF, de Tribolet N, Weller M, Kros JM, Hainfellner JA, Mason W, Mariani L, Bromberg JE, Hau P, Mirimanoff RO, Cairncross JG, Janzer RC, Stupp R (2005) MGMT gene silencing and benefit from temozolomide in glioblastoma. New Engl J Med 352: $997-1003$

Hulsebos TJ, Troost D, Leenstra S (2004) Molecular-genetic characterisation of gliomas that recur as same grade or higher grade tumours. J Neurol Neurosurg Psychiatry 75: 723-726

Inda MM, Fan X, Munoz J, Perot C, Fauvet D, Danglot G, Palacio A, Madero P, Zazpe I, Portillo E, Tunon T, Martinez-Penuela JM, Alfaro J, Eiras J, Bernheim A, Castresana JS (2003) Chromosomal abnormalities in human glioblastomas: gain in chromosome $7 \mathrm{p}$ correlating with loss in chromosome 10q. Mol Carcinog 36: 6-14

Kang CS, Pu PY, Li YH, Zhang ZY, Qiu MZ, Huang Q, Wang GX (2005) An in vitro study on the suppressive effect of glioma cell growth induced by plasmid-based small interference RNA (siRNA) targeting human epidermal growth factor receptor. J Neurooncol 74: 267-273

Lamszus K, Brockmann MA, Eckerich C, Bohlen P, May C, Mangold U, Fillbrandt R, Westphal M (2005) Inhibition of glioblastoma angiogenesis and invasion by combined treatments directed against vascular endothelial growth factor receptor-2, epidermal growth factor receptor, and vascular endothelial-cadherin. Clin Cancer Res 11: 4934-4940

Leuraud P, Taillandier L, Medioni J, Aguirre-Cruz L, Criniere E, Marie Y, Kujas M, Golmard JL, Duprez A, Delattre JY, Sanson M, Poupon MF (2004) Distinct responses of xenografted gliomas to different alkylating agents are related to histology and genetic alterations. Cancer Res 64: $4648-4653$

Liu L, Markowitz S, Gerson SL (1996) Mismatch repair mutations override alkyltransferase in conferring resistance to temozolomide but not to 1,3bis(2-chloroethyl)nitrosourea. Cancer Res 56: 5375-5379

Liu W, James CD, Frederick L, Alderete BE, Jenkins RB (1997) PTEN/ MMAC1 mutations and EGFR amplification in glioblastomas. Cancer Res 57: $5254-5257$

Mao X, Hamoudi RA (2000) Molecular and cytogenetic analysis of glioblastoma multiforme. Cancer Genet Cytogenet 122: 87-92

Nagane M, Levitzki A, Gazit A, Cavenee WK, Huang HJ (1998) Drug resistance of human glioblastoma cells conferred by a tumor-specific mutant epidermal growth factor receptor through modulation of Bcl-XL and caspase-3-like proteases. Proc Natl Acad Sci USA 95: 5724-5729

Nigro JM, Misra A, Zhang L, Smirnov I, Colman H, Griffin C, Ozburn N, Chen M, Pan E, Koul D, Yung WK, Feuerstein BG, Aldape KD (2005) Integrated array-comparative genomic hybridization and expression array profiles identify clinically relevant molecular subtypes of glioblastoma. Cancer Res 65: 1678-1686

Ohgaki H, Dessen P, Jourde B, Horstmann S, Nishikawa T, Di Patre PL, Burkhard C, Schuler D, Probst-Hensch NM, Maiorka PC, Baeza N, Pisani P, Yonekawa Y, Yasargil MG, Lutolf UM, Kleihues P (2004) Genetic pathways to glioblastoma: a population-based study. Cancer Res 64: $6892-6899$

Pirker C, Holzmann K, Spiegl-Kreinecker S, Elbling L, Thallinger C, Pehamberger H, Micksche M, Berger W (2003) Chromosomal imbalances in primary and metastatic melanomas: over-representation of essential telomerase genes. Melanoma Res 13: 483-492

Pirker C, Raidl M, Steiner E, Elbling L, Holzmann K, Spiegl-Kreinecker S, Aubele M, Grasl-Kraupp B, Marosi C, Micksche M, Berger W (2004) Whole genome amplification for CGH analysis: linker-adapter PCR as the method of choice for difficult and limited samples. Cytometry 61A: $26-34$

Rabik CA, Njoku MC, Dolan ME (2006) Inactivation of O6-alkylguanine DNA alkyltransferase as a means to enhance chemotherapy. Cancer Treat Rev 32: $261-276$

Rasheed BK, Stenzel TT, McLendon RE, Parsons R, Friedman AH, Friedman HS, Bigner DD, Bigner SH (1997) PTEN gene mutations are seen in high-grade but not in low-grade gliomas. Cancer Res 57: $4187-4190$

Saxena A, Shriml LM, Dean M, Ali IU (1999) Comparative molecular genetic profiles of anaplastic astrocytomas/glioblastomas multiforme and their subsequent recurrences. Oncogene 18: 1385-1390

Schlegel J, Merdes A, Stumm G, Albert FK, Forsting M, Hynes N, Kiessling M (1994a) Amplification of the epidermal-growth-factor-receptor gene correlates with different growth behaviour in human glioblastoma. Int $\mathrm{J}$ Cancer 56: $72-77$

Schlegel J, Stumm G, Brandle K, Merdes A, Mechtersheimer G, Hynes NE, Kiessling M (1994b) Amplification and differential expression of members of the erbB-gene family in human glioblastoma. J Neurooncol 22: $201-207$

Schmidt-Kittler O, Ragg T, Daskalakis A, Granzow M, Ahr A, Blankenstein TJ, Kaufmann M, Diebold J, Arnholdt H, Muller P, Bischoff J, Harich D, Schlimok G, Riethmuller G, Eils R, Klein CA (2003) From latent disseminated cells to overt metastasis: genetic analysis of systemic breast cancer progression. Proc Natl Acad Sci USA 100: 7737-7742

Scott CB, Scarantino C, Urtasun R, Movsas B, Jones CU, Simpson JR, Fischbach AJ, Curran Jr WJ (1998) Validation and predictive power of Radiation Therapy Oncology Group (RTOG) recursive partitioning analysis classes for malignant glioma patients: a report using RTOG 90-06. Int J Radiat Oncol Biol Phys 40: 51-55

Shinojima N, Tada K, Shiraishi S, Kamiryo T, Kochi M, Nakamura H, Makino K, Saya H, Hirano H, Kuratsu J, Oka K, Ishimaru Y, Ushio Y (2003) Prognostic value of epidermal growth factor receptor in patients with glioblastoma multiforme. Cancer Res 63: $6962-6970$

Silber JR, Bobola MS, Ghatan S, Blank A, Kolstoe DD, Berger MS (1998) O6methylguanine-DNA methyltransferase activity in adult gliomas: relation to patient and tumor characteristics. Cancer Res 58: $1068-1073$

Smith JS, Jenkins RB (2000) Genetic alterations in adult diffuse glioma: occurrence, significance, and prognostic implications. Front Biosci 5: D213-D231

Spiegl-Kreinecker S, Buchroithner J, Elbling L, Steiner E, Wurm G, Bodenteich A, Fischer J, Micksche M, Berger W (2002) Expression and functional activity of the ABC-transporter proteins P-glycoprotein and multidrug-resistance protein 1 in human brain tumor cells and astrocytes. J Neurooncol 57: 27-36

Stupp R, Mason WP, van den Bent MJ, Weller M, Fisher B, Taphoorn MJ, Belanger K, Brandes AA, Marosi C, Bogdahn U, Curschmann J, Janzer RC, Ludwin SK, Gorlia T, Allgeier A, Lacombe D, Cairncross JG, Eisenhauer E, Mirimanoff RO (2005) Radiotherapy plus concomitant and adjuvant temozolomide for glioblastoma. New Engl J Med 352: 987-996

Trivedi RN, Almeida KH, Fornsaglio JL, Schamus S, Sobol RW (2005) The role of base excision repair in the sensitivity and resistance to temozolomide-mediated cell death. Cancer Res 65: 6394-6400

van den Bent MJ, Hegi ME, Stupp R (2006) Recent developments in the use of chemotherapy in brain tumours. Eur J Cancer 42: 582-588

Wiltshire RN, Rasheed BK, Friedman HS, Friedman AH, Bigner SH (2000) Comparative genetic patterns of glioblastoma multiforme: potential diagnostic tool for tumor classification. Neuro-oncology 2: 164-173

Zhu A, Shaeffer J, Leslie S, Kolm P, El-Mahdi AM (1996) Epidermal growth factor receptor: an independent predictor of survival in astrocytic tumors given definitive irradiation. Int J Radiat Oncol Biol Phys 34: 809-815

Zhu Y, Parada LF (2002) The molecular and genetic basis of neurological tumours. Nat Rev Cancer 2: 616-626 